\title{
A Research of self-help ventilator Sharing based on Internet of Things in Hospital
}

\section{XB Chen ( $\nabla$ chenxuebin116@163.com )}

China-Japan Friendship Hospital https://orcid.org/0000-0002-4628-4040

\section{Z An}

China-Japan Friendship Hospital

TQ Li

Chinese Academy of Medical Sciences \& Peking Union Medical College Fuwai Hospital

\section{J Duan}

China-Japan Friendship Hospital

\section{DJ Song}

China-Japan Friendship Hospital

$Y$ Lin

China-Japan Friendship Hospital

\section{QL Wu}

China-Japan Friendship Hospital

\section{Gao}

China-Japan Friendship Hospital

\section{Yan}

China-Japan Friendship Hospital

\section{Research article}

Keywords: Ventilator Sharing, Internet of Things, Self-help, Hospital

Posted Date: October 29th, 2020

DOl: https://doi.org/10.21203/rs.3.rs-29120/v2

License: (c) (i) This work is licensed under a Creative Commons Attribution 4.0 International License.

Read Full License 


\section{Abstract}

Background: To solve the problem of medical equipment sharing in clinical emergency rescue between different units in hospital, especially for ventilator.

Methods: In the research a self-help ventilator sharing mode based on Internet of Things is introduced, and six special programs for basic security, quality control, clinical operation, disinfection, cost estimation, and health technology assessment are formulated to support the project.

Results: An Internet of Things mobile APP is developed, and the running status and real-time location of ventilators can be got and spare ventilators can be shared by Medical stuff themselves on the APP. The 6 special programs are applied to support the self-service ventilator sharing mode. For trial operations of six months, 15 spare ventilators are taken in the pool of shared equipment, which are shared for 16799 hours by 7 clinical units.

Conclusions: The self-service of ventilator sharing mode meets the clinical need for equipment for emergency rescue and improves efficiency, which makes a useful exploration for the innovation management for medical equipment by Internet of Things in hospital.

\section{Background}

Ventilator as a medical equipment for emergency and life support, which can partially or completely alternative breath of patients, has been widely used in routine clinical practice currently. Mechanical ventilator has become more popular, because its application can be expanded from ICU (intensive care unit) to general unit. Yet, how to coordinate the use of ventilator between clinical units is a challenging task. It is well known that information-driven management of ventilator can ensure its quality and safety, and improve the efficiency and effectiveness of clinical use $[[1],[2],[3]]$.

Internet of Things is an effective equipment management technology, and it has been applied to many aspects of life $e^{[[4],[5]]}$. There is evidence that applying Internet of Things on medical equipment can greatly improve the management level of medical equipment. On the basis of mobile Internet of Things App, the status of ventilator can be monitored in real time and remotely[[6-8]]. In addition, the quality control of ventilator can be achieved automatically and maintenance can be supervised retroactively, and training for clinical use can be carried out both online and offline ${ }^{[[9]]}$.

The allocation of unusual medical equipment in a hospital for emergency rescue is difficult because its status and location cannot be ascertained, necessitating the immediate settlement of this problem. The Internet of Things-based mode represented by bicycle sharing is a model of good practice ${ }^{[10,11]]}$, from which emergency allocation of medical equipment can draw some lessons. A question facing us is that whether the sharing mode used to optimize the distribution of medical resources and solve the problem of emergency allocation of medical equipment in hospitals is practical. To shed some light on this question, we prepared to take ventilator as an example to analyze the feasibility of sharing allocation of 
medical equipment in our hospital, and further proposed a scheme for the allocation of medical equipment in clinical emergency rescue.

\section{Methods}

\section{Construction of self-help shared platform for mechanical ventilator}

Internet of Things is employed to carry out self-service sharing and borrowing of ventilator from four levels: equipment layer, perception layer, network layer, and application layer.

\section{Equipment layer}

Equipment layer mainly refers to the mechanical ventilator equipment used in the self-help shared mode. In this part, appropriate brand and model of mechanical ventilator is selected according to clinical usage habits and equipment characteristics. Two kinds of ventilator are chosen as shared ventilator, Servo-S of Maquet and $\mathrm{Pb840}$ of Tyco, which are widely used in clinical practice and can be disinfected conveniently. The standard communication, transport protocol, and transport port of ventilator should be acquired from equipment company.

\section{Perception layer}

For the self-help mode of ventilator, the running status and position data of ventilator should be acquired in real time by perception layer. Tripartite data collector ("Intelligent collector" from Beijing HuiZeZhiXin Technology Co., Ltd) was chosen for real-time data collect from ventilator, and the location of the ventilator was acquired by the RFID (Radio Frequency Identification) or Bluetooth tag location.

\section{Network layer}

Network layer is the information channel for sharing data transmission, and it refers to the protocol of information transmission among different system levels. Network layer mainly includes four parts of network data transmission: (i) device data collector in the perception layer collects and transmits the information of device layer through device protocol by itself; (ii) device data collector in perception layer transmits collected data to the data receiving terminal through the LAN(Local Area Network) or WAN(Wide Area Network) protocols; (iii) data of devices receiving terminal transmit to the database according to the transmission protocols of Ethernet; (iv) data in the database will be transmitted to the application terminal of personal computers and mobile application Ethernet or mobile network transmission protocols.

\section{Application layer}

Application layer contains mobile application and personal application, which are used to carry out and supervise for the self-help process of ventilator. 
The mode of self-help shared ventilator allocation is based on the use condition of ventilator in clinical practice, mainly including equipment list and essential information, use efficiency, maintenance information, and running data of ventilator. Six specific schemes are developed, including basic security scheme, quality and control scheme for shared ventilator, guarantee of clinical operation, disinfection scheme for shared ventilator, cost estimation and performance incentive scheme, and health technology assessment scheme.

\subsection{Basic security scheme}

The goal of this scheme is to ensure the operability of the self-help shared process and the safety of equipment in the process. The scheme contains four contents: the setting-up of shared equipment pool, design of shared process and optimization, the development and optimization of shared software, and location management of shared equipment.

\subsubsection{Setting-up shared equipment pool}

Shared ventilators in the pool come from the idle equipment in clinical department. By analyzing running data collected by the data collector of the perception layer of the Internet of Things, we found that nearly half of the mechanical ventilators are idle in clinical departments, especially in ICU. We choose the commonly used ventilator in clinical. At first, 8 ventilators were selected and unified as a self-help shared ventilator into the shared pool. The difficulty to built shared pool is to consult with clinical units, so running data from Internet of Things system are very important to advice clinical units to incorporate idle equipment into shared pool.

\subsubsection{Design of shared process and optimization}

The process of the self-help shared ventilator is designed. We design the link of process with clinical units, hospital infection control office and application software developers. The process of sharing equipment should not be too complicated, and the characteristics of disinfection after using medical equipment should be taken into account. The optimization of the process is continuous to make the selfhelp process smooth.

\subsubsection{Development of self-help application software}

After the shared process is determined, self-help application software should be developed, which contains software in mobile application and personal computer application. In software development, backstage personnel information, equipment information, and the generation of shared reports should be considered. In this part, medical department and software developers should work closely to ensure the friendly operation interface of the software.

\subsubsection{Location management of shared equipment}


In the basic security scheme of the self-help ventilator shared allocation mode, it is important to against loss of the equipment after use. In this part, we guarantee the security of equipment by two ways: one is that the clinical stuff who participated in the process need background certification, and the other is the real-time location supervision and fixed-point borrowing and return of equipment in electronic fence. The medical stuff who participate in the self-help shared mode need to apply and provide the name, ID (identification) number and contact information to the administrative department.

For the real-time location management of the equipment, we provide two solutions: one is based on Bluetooth communication equipment location, and the other is based on RFID technology equipment location. Signal generators or RFID tags are installed on shared devices, and location information of the devices is received by data beacons or receivers installed between floors. Only when the shared devices enter the set electronic fence area, the borrowing and returning process can be started. The location management of equipment needs cooperation with clinical departments, information departments to smooth implementation

\subsection{Quality and control scheme for shared ventilator}

The implementation of this scheme is to ensure the stability of equipment performance parameters and improve the reliability of clinical operation of equipment, which contains four parts: routine quality control of shared equipment, three-level maintenance system of equipment, two-way traceability of maintenance, and online and offline training and learning. In this part, we need cooperate with medical management departments, clinical departments and equipment manufacturers to ensure the quality and safety of ventilators.

\subsubsection{Routine quality control of shared equipment}

Routine quality control of shared equipment is according to national ventilator measurement standards, The quality control of shared ventilator is carried out at least once annually, and parameters of ventilator are tested with VT900 flowmeter of fluke.

\subsubsection{Maintenance}

In daily maintenance, three-level maintenance system is formulated, and it includes three aspects: clinical use maintenance as the first level, bio-medical department maintenance as the second level, and manufacturer maintenance as the third level. The contents of the three-grade maintenance are different. Figure 3 shows the contents of three-grade maintenance.

The messages of equipment maintenance noticed by mobile application can ensure two-way traceability of equipment maintenance, keep on-line statistics of equipment failure and maintenance data, make preventive maintenance in advance, and ensure normal status of equipment.

\subsubsection{Online and offline training}


The manual and operation video of the ventilator can be acquired through the mobile application, and the needs of clinical stuff can feedback on App. Training videos, operation videos, brief manual, instructions and other related documents can also be uploaded to the App from clinical stuff.

\subsection{Guarantee of clinical operation}

The purpose of this scheme is to ensure the accuracy and safety of clinical ventilator operation in the process of clinical use. Although the ventilator selected in the shared pool is routine equipment, some medical stuff still don't know how to set parameters according to the status of patients. In order to guarantee the clinical use of shared ventilator, the main contents of the scheme include: ICU doctor's guidance for the first use, training for operation skills of ventilator by manufacture, adding simple operation manual, and so on. In this part, the bio-medical department should be kept in communication with ICU departments and other clinical departments to ensure that the relevant technical support can be in place in time.

\subsection{Disinfection scheme for shared ventilator}

The purpose of this part is to ensure the effect of sharing ventilator disinfection and preventing nosocomial infection. The contents of this scheme include: establishing the disinfection guideline for shared ventilator, strengthening the training of equipment disinfection operation, supervising the use of App disinfection operation, and monitoring the disinfection effect of shared equipment. To complete scheme bio-medical departments, hospital infection control office, ICU and general clinical departments need to cooperate together to ensure the disinfection effects of shared equipment after use.

First, disinfection guidelines for shared ventilator were formulated, including the basis of the guideline, basic requirements of for cleaning and disinfection, parts disinfection requirements, stuff requirement, and the disinfection methods for shared ventilators after use. Second, based on the guidelines, special training should be carried out for medical stuff that participate in the process of shared ventilator to ensure the effectiveness of disinfection. In the mobile application the patients should be classified into infectious and noninfectious groups, which can be useful for disinfection. When returning the shared ventilator, the photos during the disinfection process must be upload to mobile application. Finally, the managers of hospital infection control office can regularly monitor the disinfection of shared equipment after use to ensure the disinfection effect of the shared ventilators.

\subsection{Cost estimation and performance incentive scheme}

This scheme is made to ensure the interest of departments that participate in the self-help shared process. The contents of the scheme include cost analysis of clinical ventilator use, and cost for hardware and software for the self-help shared ventilator process. To complete the scheme, hospital finance department, performance management department and clinical department should cooperate with each other. 
First, the running costs for clinical use and cost allocation between clinical unit are carried out. Researchers preliminarily calculate per hour running cost of the ventilator through the activity-based costing method. After consulting with departments who take part in the process, running cost only contains the depreciation cost and maintenance cost of the units, and allocated to borrowing units as performance reward to the shared unit, which spares equipment into the shared pool.

\subsection{Hospital based health technology assessment for shared allocation}

The self-help shared mode is assessed with HB-HTA (hospital based health technology assessment) using real world data obtained from clinical pilot, and the aspect assessment includes technical characteristics of the self-help shared mode, the safety for clinical use, the effectiveness for clinical use, the economic assessment, and social effects assessment. The results of HB-HTA support the decision that self-help shared mode should be carried out in hospital.

\subsubsection{Assessment for technical characteristics}

The assessment for technical characteristics of self-help shared allocation mode compared the new equipment shared mode with traditional equipment allocation methods.

\subsubsection{Assessment for safety of clinical use}

In this part, the safety of clinical use is assessed from 3 aspect, the safety operation of ventilator for clinical use, the effect of disinfection of shared ventilator after use, the running reliability of shared ventilator.

\subsubsection{Assessment for effectiveness of clinical use}

The assessment for effectiveness is carried out from the guarantee of the hardware and software of the mode and the clinical use effectiveness.

\subsubsection{Economic assessment for the self-help shared mode}

The economic evaluation of the project is mainly carried out in two aspects: (1) the cost of the project implementation, and (2) the benefit of the project implementation.

\subsubsection{Social effects assessment for the self-help shared mode}

The self-help shared mode provides a new and effective solution for the allocation and use of emergency and life support medical equipment in emergency rescue, which may improves the success rate of emergency rescue, and the mode do not have ethical risk in clinical.

\section{Data Analysis}

The data of time and charges used to assess the economic performance of the project are acquired from the Internet of Things system and HIS, and they are objective to reflect the results of self-help ventilator 
sharing mode.

\section{Results}

According to the specific scheme of self-help ventilator shared allocation, the project was carried out in November 2018. Three department of the hospital (main department, north department, and international department of hospital) participated in the program. The results are better than that we estimated and the following will analyze the results of the Implementation of the self-help ventilator shared allocation mode.

\section{The equipment layer}

The equipment layer of Internet of Things for the self-help shared mode is the ventilators selected for shared pool. The selected ventilator must transport running data to perception layer by the standard communication and transport protocol through data communication transport port (Table 1).

\section{Perception layer}

We choose a tripartite data collector from Huizezhixin limit, which can collect running data from ventilators by standard communication and transport protocol which provided by the company of the ventilators. Routine data which include 21 parameters and 23 alarms signals can be obtained from equipment and remote monitored (Table 2).

\section{Network layer}

The network layer in the program includes four parts of network for transmission: (1) the device data collector in the perception layer collects and transmits the information of the device layer through the protocol of the device itself; (2) the device data collector in the perception layer transmits the collected data to the data receiving terminal through the LAN or WAN protocol; (3) the data of devices receiving terminal transmitted to the database according to the transmission protocol of ethernet; (4) Data in the database will be transmitted to the application terminal of personal computer and mobile application Ethernet or mobile network transmission protocol.

\section{Application layer}

The application layer contains mobile application and personal computer application. The mobile application can supervise the running status of the remotely and the personal computer application can generate the use record automatically.

\section{Basic security scheme}

\section{Pool of shared ventilators}


At first 12 ventilators are selected as shared equipment to set up the pool, which contains 11 Servo-s/i ventilators and $1 \mathrm{~Pb} 840$ ventilator. All the selected ventilators are idle equipment from clinical unit. After pilot for some time, 3 other idle ventilators from the dispatching center of the Medical Engineering Department have been incorporated into the pool. Now, there are 15 ventilators are in the pool of shared equipment, including 12 Servo-s/i ventilators, $1 \mathrm{~Pb} 840$ ventilator, 2 XTC ventilators, which is enough for emergency rescue use (Table 3).

\section{Clinical unit and stuff participation}

During the process, 21 clinical units in the hospital participated in the self-help shared ventilator allocation and 232 clinical staff participated in the process were authorized and attend the training for the shared mode (Table 4).

\section{Application and software}

For the whole process, there are 14 steps form clinical authorization to self-help sharing application. Whole shared process was managed by Medical Engineering Department for the status of shared ventilators and clinical applications of different departments. Usage time of shared ventilators were submitted by Medical Engineering Department to Hospital Finance Department for cost and performance of ventilator borrowing and sharing departments. To ensure the disinfection effect of shared ventilators, regular sampling and testing for pathogenic microorganisms on ventilators were carried out by Hospital Disinfection Control Department (Figure 1).

The mode of self-help sharing ventilator was constructed on the technique of loT (Figure 2). Status and location information of shared ventilators were collected by data collector and RFID/Bluetooth. Data collected were analyzed by the server and displayed on App and PC software. The mobile application software was designed based on the process of self-help sharing ventilator (Figure 3). Clinicians were personal authorized by medical equipment department to use the App for self-help shared ventilators.

\section{Location management}

The location management of the self-help shared allocation of ventilator are carried out with two solutions: one is based on Bluetooth communication equipment location (Table 5), the other is based on RFID technology equipment location (Table 6). Signal generators or RFID tags are installed on the shared devices, and the location information of the devices is received by data beacons or receivers installed between floors. Only when the shared devices enter the set electronic fence area can the borrowing and returning process can be started. The location management of equipment needs the cooperation of clinical departments and information departments.

\section{Quality control}

The quality control of the shared ventilator are measured with VT900 flow-meter from fluke, the flow meter is authorized by national institute of metrology, China, and the record is YSyx2018-0847. The 
results show that the quality of all the ventilators in shared pool meet the national standard(results will be show in another research). For the maintenance of the shared ventilator, there are only several time without any fee.

\section{Clinical operation and disinfection}

From November of 2018 to June of 2019 , the self-help shared ventilators are used normally and disinfection supervision from the hospital infection control office shows the load of pathogenic bacteria is Compliance with disinfection guideline.

\section{Cost estimation and performance incentive}

Per hour running cost of the ventilator were calculated through the activity-based costing method. After consulting with departments take part in the process, the running cost only contains the depreciation cost and maintenance cost during the clinical use of ventilator. Results show that the depreciation cost is about 3yuan/hour, and the maintenance cost calculated with the last year is about 0.82 yuan/hour. After refer to other hospital in Beijing, the running cost of shared ventilator is set as 4 yuan/hour. The money will be deducted from borrowing unit as performance intensive give the lending unit.

\section{HB-HTA}

Compared the self-help shared allocation mode with traditional medical equipment allocation mode, which contains Interdepartmental equipment lending mode, equipment distribution department, ventilator Administration department. In the aspects of equipment reliability, clinical operation and maintenance, disinfection, effect and cost, the self-help mode is better than traditional mode (table 7).

Data analysis showed that for about 5 months usage, 7 clinical units use the shared ventilator for 17 times, and the total time of the shared ventilator is about 16799 hours under the self-help shared process, which can bring about $¥ 420$ thousand income for hospital (table 8 ). All the ventilators in shared pool were idled before shared, after that 13 of 15 ventilators were shared for clinical application and average working time is about 8.6 hours per day for each ventilator. The idle rate of self-help shared ventilators is from $100 \%$ to $13.3 \%$ in about 5 months.

After the pilot project of self-help shared mode, the purchase cost of ventilators in hospitals has been greatly reduced. In 2018, except for the new PICU in pediatrics, only four new ventilators are purchased, and the other departments have adopted the method of sharing allocation, which saves more than 2.5 million yuan for the purchase of equipment in hospitals.

\section{Discussion}

In our hospital there are 4 departments in different districts of our city, which are the center department, Characteristic department, the western district, healthcare department and the international department. There are 275 ventilators (invasive and non-invasive ventilators) available in the hospital, including 10 
brands and 25 models, which covering nearly all basic types of ventilators currently. The ventilators distributed in 15 clinical units of hospital囚include surgical intensive care unit, intensive care unit, emergency department, and department of operation and anesthesia.

According to the data provided by HIS (hospital information system), the usage status of ventilators in our hospital is good, but there is still a problem of mutual borrowing among clinical departments. Based on the data of HIS, total using time of ventilators is more than 600,000 hours in the year of 2018 , and average use time of each ventilator was more than 11 hours per day. In 2018, 59 clinical units in hospital used ventilators, and the usage time of 44 clinical unit which do not have ventilator is about 62,600 hours. For shortage of personnel in the hospital medical equipment allocation center, more than 60,000 hours usage time of ventilators are borrowed privately among clinical departments, which is inefficient and troublesome.

At present, the management of ventilator in medical institutions mainly depends on the manual of medical staff with low efficiency. Some problems existing in the process, such as inadequate quality control management, hard to trace for maintenance of equipment, improper clinical use, and the improper handling for alarms of ventilator. Our hospital has started the information management of ventilators based on the Internet of Things since the year 2017, and by mobile application we can monitor the status of ventilator by the analysis of the using data of ventilator real-time and remotely, trace equipment maintenance, collect and analyze quality control data automatically. Online and offline training can also be carried out by the mobile application. The information management of ventilator based on the Internet of Things provides data and hardware support for the ventilator sharing allocation project, and provides guarantee for the smooth development of the project.

Self-help shared allocation of medical equipment is an innovative management mode of medical equipment based on technology of Internet of Things. This model plays an important role in solving the uneven distribution of clinical medical resources and improving the efficiency of medical equipment. supervising the status of medical equipment in shared allocation is an important prerequisite for the implementation of shared allocation. Data acquisition and location technology of medical equipment based on Internet of Things ensures the implementation of this project.

In this project, the hospital of traditional Chinese medicine has built an information platform of life cycle management of medical equipment based on Internet of Things, which can provide real-time status information for the implementation of the project. At the same time, the pre-hospital consumables management also uses the replenishment system based on RFID positioning, which can provide support for the equipment positioning of the project. Therefore, the construction of this level is not considered in the implementation of the project. The cost of the station. In hospitals without information management platform, the acquisition cost of equipment hardware collector and information software is also a small part of the cost compared with the income and savings of project implementation.

In the time, the self-help shared ventilator only for invasive ventilator, excluding non-invasive and transporting ventilators. In next step, we should try to consider the commonly used mode in different 
hospitals to ensure the convenience of clinical use.

The smooth development of the project requires the collaborative efforts of medical management departments and many related departments of the hospital, including clinical departments, information departments, financial departments, performance management departments, hospital management departments, medical departments. Each department has different responsibilities, in the program has been introduced on the participation of various departments in the project. The development of the project requires the collaboration of all departments, so the medical and industrial departments as the initiator need to do a good job of the relevant program plans to ensure the smooth implementation of the project.

The primary limitation of our study is that the disinfection of ventilators shared in different clinical unit may not homogenized although we have developed detailed disinfection guidelines and strict supervision both in clinical practice and on App, for some disinfection processes of different accessories are too complicated to master for someone unfamiliar with ventilators. To overcome this problem, continuous training required for medical stuff of clinical unit participated in ventilator sharing mode. Different with bicycle sharing, disinfection of medical equipment sharing is important for clinical use, if the problem can be well solved the ventilator sharing mode based on Internet of Things can be can extend to other medical equipment in hospitals.

\section{Conclusion}

In the study a mode of self-help ventilator sharing by Internet of Things has been proposed and pilot run in our hospital, and detailed schemes are carried out to support the project. After six months, spare ventilators are well used and satisfied the clinical need for emergency rescue. Intelligent management of medical equipment is the promising way to manage medical equipment in the future for intelligent hospitals. Shared allocation of ventilators is a pilot project of medical equipment information management, and its effectiveness needs scientific evaluation and analysis. For next steps, we will continue to optimize the details of the self-help shared allocation process of medical equipment, add assessment for the effectiveness of the mode. Under $5 \mathrm{G}$ condition, self-help shared ventilator mode is a meaningful attempt for the management of medical equipment.

\section{Abbreviations}

App: Application

ICU: Intensive Care Units

RFID: Radio Frequency Identification

LAN: Local Area Network 
WAN: Wide Area Network

ID: Identification

HB-HTA: Hospital Based Health Technology Assessment

MICU: Medical Intensive Care Units

SICU: Surgery Intensive Care Units

PICU: Pediatric Intensive Care Unit

HIS: Hospital Information System

ME: Medical Engineering Department

\section{Declarations}

Ethics approval and consent to participate: This article does not contain any studies with human participants or animals performed by any of the authors.

Consent to publication: Not Applicable

Availability of data and materials: The materials described in the manuscript, including all relevant raw data, will be freely available to any scientist wishing to use them for non-commercial purposes, without breaching participant confidentiality.

Competing interests: The authors declare that they have no competing interests,

FundingIThis study was funded by the Joint Fund of Biomedical Transformation Engineering Research Center of Beijing University of Chemical Technology and China Japan Friendship Hospital. The design of the study and collection, analysis, and interpretation of data and in writing the manuscript are supported by the Grant of the funding. (Grant No. XK2020-04, PYBZ1813, PYBZ1809).

Authors' contributions: XB Chen, TQ Li, J Duan, Y Lin contributed to the conception of the study; XB Chen contributed to manuscript draft preparation; DJ Song; QL Wu; M Gao; D Yan performed the experiments and data analyses; XB Chen, $Z$ An revised the manuscript and approved the final version. All authors have read and approved the manuscript.

Acknowledgements: We thank LT Lv of Renmin University of China, F Bai and X Lin of Bureau of Medical Administration, National Health Commission of the People's Republic of China for assistance of Health Technology Assessment. We thank J Yin of editorial department China Medical Equipment for writing assistance and valuable discussion. All the authors declare that they have no Conflict of Interest. 


\section{References}

1. Dellaca' RL, Veneroni C, Farre' R: Trends in mechanical ventilation: are we ventilating our patients in the best possible way? Breathe 2017, 13:84-98.

2. Hafiz M, Stahl J: Lung-protective Ventilation for Acute Respiratory Distress Syndrome. In Book Lungprotective Ventilation for Acute Respiratory Distress Syndrome (Editor ed.^eds.), vol. 26. pp. 109-112. City; 2019:109-112.

3. Lupton JR, Schmicker RH, Stephens S, Carlson JN, Callaway C, Herren H, Idris AH, Sopko G, Puyana JCJ, Daya MR, et al: Outcomes With the Use of Bag-Valve-Mask Ventilation During Out-of-hospital Cardiac Arrest in the Pragmatic Airway Resuscitation Trial. Academic emergency medicine : official journal of the Society for Academic Emergency Medicine 2020.

4. GONG Ren-song DS-j, FU An-ping: Design and application of quality traceability system for medical equipment based on internet of things. China Medical Equipment 2018, 15:135-137.

5. CAO Hui1 YJ, ZHENG Yunxin2, CHEN Ying2, LI Bin2, CHEN Mu1: Practice and Exploration of Regional Medical Equipment Cloud Management Platform Based on the Internet of Things. Chinese Journal of Medical Instrumentation 2018, 42:332-334,344.

6. Tun SYY, Madanian S, Mirza F: Internet of things (IOT) applications for elderly care: a reflective review. Aging Clinical and Experimental Research 2020.

7. Mulloni V, Donelli M: Chipless RFID Sensors for the Internet of Things: Challenges and Opportunities. Sensors (Basel) 2020, 20.

8. Curry J, Harris N: Powering the Environmental Internet of Things. Sensors 2019, 19:1940.

9. JINWei: Quality inspection on in-use breathing machine. Chinese Medical Equipment Journal 2017, 38:96-98.

10. Guo Y Fau - Zhou J, Zhou J Fau - Wu Y, Wu Y Fau - Li Z, Li Z: Identifying the factors affecting bikesharing usage and degree of satisfaction in Ningbo, China.

11. Chiariotti F Fau - Pielli C, Pielli C Fau - Zanella A, Zanella A Fau - Zorzi M, Zorzi M: A Dynamic Approach to Rebalancing Bike-Sharing Systems.

\section{Tables}

Table 1. The communication transport port of common ventilators

\begin{tabular}{ccc}
\hline Brand & Model & Port type \\
\hline Maquet & Servo-i, Servo-s & RS-232 port \\
Tyco & PB840 & RS-232 port \\
Dreager & Evita4, Evita XL & RS-232 port \\
Hamilton & Galileo, Raphael & RS-232 port \\
Philips & V60 & Parallel Serial port \\
\hline
\end{tabular}


Table 2. Alarm signal and parameter chosen to acquired

\begin{tabular}{|c|c|c|}
\hline NO. & ALARM & PARAMETER \\
\hline 1 & airway pressure too high & Vte \\
\hline 2 & airway pressure too low & Vti \\
\hline 3 & Exp. minute volume too high & Spont Vt \\
\hline 4 & Exp. minute volume too low & $\mathrm{Ve}$ \\
\hline 5 & O2 cinc.too high & Spont Ve \\
\hline 6 & O2 cinc.too low & Spont Rate \\
\hline 7 & galvanic cell failure & Rate \\
\hline 8 & check tubing & $\mathrm{Ti}$ \\
\hline 9 & no consistent patient effort & $\mathrm{I}: \mathrm{E}$ \\
\hline 10 & Apnea & Ppeek \\
\hline 11 & Low Battery & Pmean \\
\hline 12 & Battery drained & PEEP \\
\hline 13 & exhalation closed box technical error & O2 inlet \\
\hline 14 & safety valve test failed & $\mathrm{FiO} 2$ \\
\hline 15 & breath frequency too high & mode \\
\hline 16 & breath frequency too low & vt \\
\hline 17 & PEEP too high & $\mathrm{F}(\mathrm{L} / \mathrm{s})$ \\
\hline 18 & PEEP too low & EPAP \\
\hline 19 & inspiratory tidal volume too high & Pplat \\
\hline 20 & inspiratory tidal volume too low & Cst \\
\hline 21 & Inspiratory flow too high & Cdyn \\
\hline 22 & Inspiratory flow too low & - \\
\hline 23 & exhalation closed box changed & - \\
\hline
\end{tabular}


Table 3. The shared ventilator in the pool

\begin{tabular}{llllcccc}
\hline NO. Aera & Department Equipment Device Identification & Brand & \multicolumn{2}{c}{ Specification type Enable time } \\
\hline 1 & General & ME & Ventilator & 27575 & HAMILTON & XTC & $2009-10-30$ \\
2 & General & ME & Ventilator & 27559 & HAMILTON & XTC & $2009-10-15$ \\
\hline 3 & General & ME & Ventilator & 1374 & MAQUET & Servo-s & $2016-6-6$ \\
\hline 4 & General & SICU & Ventilator & 30989 & MAQUET & Servo-s & $2014-3-7$ \\
\hline 5 & General & SICU & Ventilator & 30988 & TYKO & PB840 & $2014-3-7$ \\
\hline 6 & General & SICU & Ventilator & 30985 & MAQUET & Servo-s & $2014-3-7$ \\
\hline 7 & General & SICU & Ventilator & 30983 & MAQUET & Servo-s & $2014-3-7$ \\
\hline 8 & General & SICU & Ventilator & 25487 & MAQUET & Servo-i & $2003-5-1$ \\
\hline 9 & General & SICU & Ventilator & 25244 & MAQUET & Servo-i & $2003-5-1$ \\
\hline 10 General & SICU & Ventilator & A00187 & MAQUET & Servo-s & $2014-3-7$ \\
\hline 11 General & SICU & Ventilator & A00118 & MAQUET & Servo-s & $2014-3-7$ \\
\hline 12 & Branch & MICU & Ventilator & 1379 & MAQUET & Servo-s & $2015-6-16$ \\
\hline 13 & Branch & MICU & Ventilator & 1378 & MAQUET & Servo-s & $2015-6-16$ \\
\hline 14 & Branch & MICU & Ventilator & 1376 & MAQUET & Servo-s & $2015-6-16$ \\
\hline 15 & Branch & MICU & Ventilator & 1391 & MAQUET & Servo-s & $2015-6-16$ \\
\hline
\end{tabular}

Table 4. The clinical unit participated and stuff authorized 
NO. Department Involved

1 Health Care Card 4

2 Department Health Care

3 Lung Transplantation Department

4 Dispatching center of the Medical Engineering Department

5 Neurology Department

6 ICU

7 Cardiology department

8 Infectious Disease Department

9 International Medical Department

$10 \mathrm{MICU}$

11 Emergency Department

12 Neurology Department

13 Neurosurgery

14 SICU

15 Gastroenterology Department

16 Department of Hematology

17 Department of Anesthesiology

18 Pediatrics Department

19 Orthopaedics Department

20 Department of General Surgery

21 Cardiology Department
Participant Authorized Department

9 Branch Department

23 Branch Department

27 Branch Department

1 Branch Department

19 Branch Department

1 Branch Department

19 Branch Department

1 General Department

3 General Department

5 General Department

19 General Department

15 General Department

37 General Department

19 General Department

1 General Department

14 General Department

3 General Department

6 General Department

3 General Department

4 General Department

3 General Department

Table 5. The location of ventilator detected by blue tooth technology

\begin{tabular}{ccccc}
\hline NO. & MAC Adress & Device Identification & Signal Intensity & Update time \\
\hline 1 & C7-01-75-BE-F1-01 & 17343 & -54 & $2019 / 7 / 2619: 42$ \\
2 & 0C-61-CF-C3-90-31 & 17337 & -65 & $2019 / 7 / 2619: 42$ \\
\hline 3 & 12-3B-6A-1B-50-C5 & 17343 & -73 & $2019 / 7 / 2619: 42$ \\
\hline 4 & 12-3B-6A-1B-50-C6 & 17337 & -77 & $2019 / 7 / 2619: 42$ \\
\hline
\end{tabular}


Table 6. The location of ventilator detected with RFID

\begin{tabular}{cclcc}
\hline Device & Device Indification & Location & Time & Status \\
\hline Ventilator & 30989 & storehouse & $2019 / 1 / 1013: 48$ & Enter \\
& storehouse & $2019 / 1 / 1516: 13$ & Leave \\
\cline { 2 - 4 } & MICU & $2019 / 3 / 7 ~ 16: 15$ & Enter \\
\hline MICU & $2019 / 3 / 7 ~ 16: 37$ & Leave \\
\hline & SICU & $2019 / 3 / 7 ~ 16: 57$ & Enter \\
\hline & SICU & $2019 / 3 / 717: 02$ & Leave \\
\hline
\end{tabular}

Table 7. Technical assessment for self-help sharing and traditional allocation

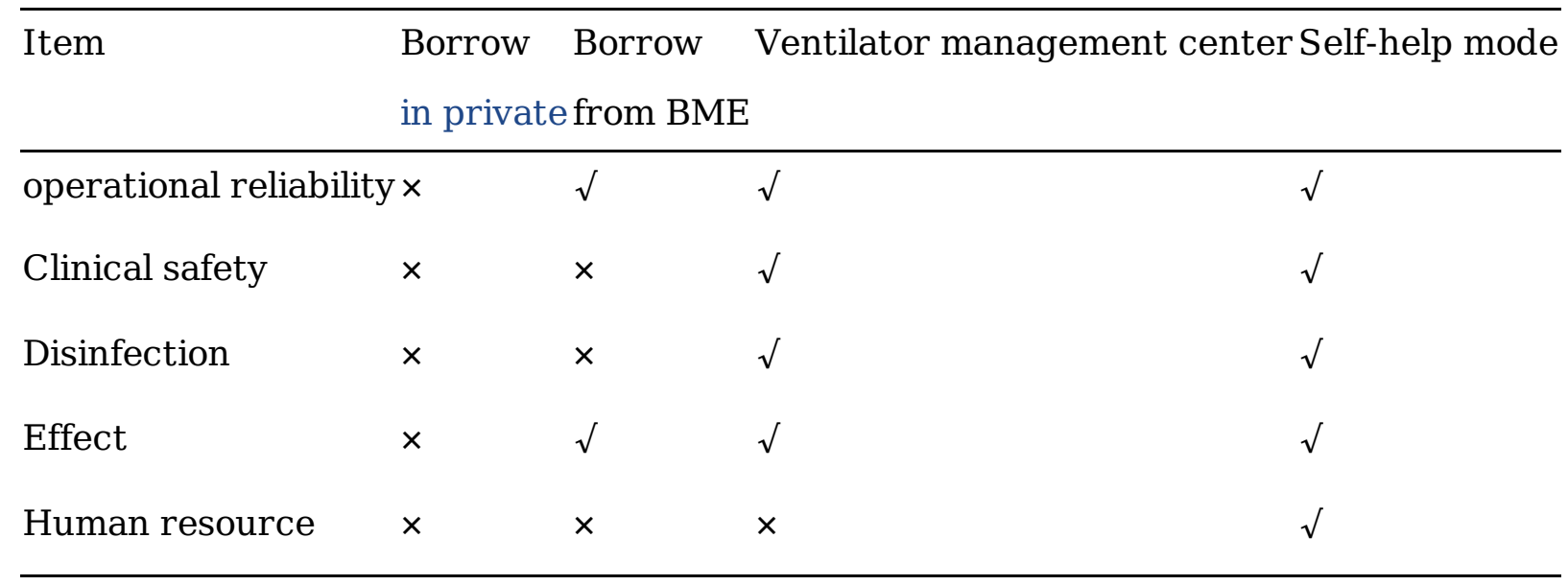

Table 8. clinical application of self-help ventilator in first 5 months 


\begin{tabular}{|c|c|c|c|c|c|c|c|c|c|}
\hline NO. & $\begin{array}{l}\text { Ventilator } \\
\text { ID }\end{array}$ & $\begin{array}{l}\text { r Borrowing } \\
\text { Time }\end{array}$ & $\begin{array}{l}\text { Return } \\
\text { time }\end{array}$ & $\begin{array}{l}\text { Borrowing } \\
\text { clinician }\end{array}$ & $\begin{array}{l}\text { Borrowing } \\
\text { department }\end{array}$ & $\begin{array}{l}\text { Shared } \\
\text { time } \\
\text { (hour) }\end{array}$ & $\begin{array}{l}\text { Charge for clinical } \\
\text { application (¥) }\end{array}$ & $\begin{array}{l}\text { Cost of borrowing } \\
\text { department }(¥)\end{array}$ & $\begin{array}{c}\text { Performance for } \\
\text { shared department } \\
(¥)\end{array}$ \\
\hline 1 & A00118 & $\begin{array}{l}2018-11-15 \\
09: 42\end{array}$ & $\begin{array}{l}2018-11- \\
2712: 07\end{array}$ & Xie Wan-mu & $\begin{array}{l}\text { International } \\
\text { Medical } \\
\text { Department }\end{array}$ & 290 & 7250 & 1160 & 1160 \\
\hline 2 & A00118 & $\begin{array}{l}\text { 2019-01-02 } \\
16: 14\end{array}$ & $\begin{array}{l}2019-01- \\
1116: 52\end{array}$ & Zuo Ying & Neurosurgery & 216 & 5400 & 864 & 864 \\
\hline 3 & A00118 & $\begin{array}{l}2019-01-29 \\
10: 40\end{array}$ & $\begin{array}{l}\text { 2019-02- } \\
1407: 54\end{array}$ & Liu Bao & SICU & 381 & 9525 & 1524 & 1524 \\
\hline 4 & A00118 & $\begin{array}{l}2019-02-19 \\
16: 55\end{array}$ & $\begin{array}{l}2019-03- \\
2000: 00\end{array}$ & $\begin{array}{l}\text { Gao Chen- } \\
\text { yan }\end{array}$ & Neurosurgery & 679 & 16975 & 2716 & 2716 \\
\hline 5 & 30988 & $\begin{array}{l}\text { 2019-01-08 } \\
15: 41\end{array}$ & $\begin{array}{l}2019-03- \\
2000: 00\end{array}$ & Liu Bao & SICU & 1688 & 42200 & 6752 & 6752 \\
\hline 6 & 25244 & $\begin{array}{l}\text { 2019-01-07 } \\
16: 29\end{array}$ & $\begin{array}{l}2019-03- \\
2000: 00\end{array}$ & Liu Bao & SICU & 1711 & 42775 & 6844 & 6844 \\
\hline 7 & 30983 & $\begin{array}{l}\text { 2019-01-07 } \\
16: 29\end{array}$ & $\begin{array}{l}2019-03- \\
2000: 00\end{array}$ & Liu Bao & SICU & 1711 & 42775 & 6844 & 6844 \\
\hline 8 & 25487 & $\begin{array}{l}\text { 2019-01-08 } \\
10: 18\end{array}$ & $\begin{array}{l}2019-03- \\
2000: 00\end{array}$ & Liu Bao & SICU & 1693 & 42325 & 6772 & 6772 \\
\hline 9 & 30985 & $\begin{array}{l}2019-01-29 \\
10: 41\end{array}$ & $\begin{array}{l}2019-03- \\
2000: 00\end{array}$ & Liu Bao & SICU & 1189 & 29725 & 4756 & 4756 \\
\hline 10 & 30989 & $\begin{array}{c}2019-01-29 \\
10: 41\end{array}$ & $\begin{array}{l}2019-03- \\
2000: 00\end{array}$ & Liu Bao & SICU & 1189 & 29725 & 4756 & 4756 \\
\hline 11 & 27559 & $\begin{array}{l}2019-01-30 \\
09: 41\end{array}$ & $\begin{array}{l}2019-02- \\
1409: 54\end{array}$ & Zhang Hua & $\begin{array}{l}\text { Emergency } \\
\text { Department }\end{array}$ & 360 & 9000 & 1440 & 1440 \\
\hline 12 & 27575 & $\begin{array}{c}2019-01-31 \\
10: 45\end{array}$ & $\begin{array}{l}2019-02- \\
1409: 55\end{array}$ & Zhang Hua & $\begin{array}{l}\text { Emergency } \\
\text { Department }\end{array}$ & 335 & 8375 & 1340 & 1340 \\
\hline 13 & A00118 & $\begin{array}{l}2019-02-14 \\
17: 50\end{array}$ & $\begin{array}{l}2019-02- \\
2016: 47\end{array}$ & Zuo Ying & Neurosurgery & 142 & 3550 & 568 & 568 \\
\hline 14 & A00187 & $\begin{array}{l}\text { 2019-03-04 } \\
\text { 09:12 }\end{array}$ & $\begin{array}{l}2019-03- \\
2000: 00\end{array}$ & Wu Jian-ying & $\begin{array}{l}\text { Pediatrics } \\
\text { Department }\end{array}$ & 374 & 9350 & 1496 & 1496 \\
\hline 15 & 1391 & $\begin{array}{l}2019-01-30 \\
08: 57\end{array}$ & $\begin{array}{l}2019-03- \\
2000: 00\end{array}$ & Che Hai-lin & $\begin{array}{l}\text { Cardiology } \\
\text { department }\end{array}$ & 1167 & 29175 & 4668 & 4668 \\
\hline 16 & 1378 & $\begin{array}{l}2019-01-02 \\
18: 52\end{array}$ & $\begin{array}{l}2019-01- \\
3015: 37\end{array}$ & Zheng Yuan & $\begin{array}{l}\text { Cardiology } \\
\text { department }\end{array}$ & 668 & 16700 & 2672 & 2672 \\
\hline \multirow[t]{2}{*}{17} & 1379 & $\begin{array}{c}2018-11-14 \\
17: 33\end{array}$ & $\begin{array}{l}2019-03- \\
2000: 00\end{array}$ & Sun Jing & $\begin{array}{c}\text { Lung } \\
\text { transplantation } \\
\text { Department } \\
\end{array}$ & 3006 & 75150 & 12024 & 12024 \\
\hline & & & & & & 16799 & 419775 & 67196 & 67196 \\
\hline
\end{tabular}

\section{Figures}




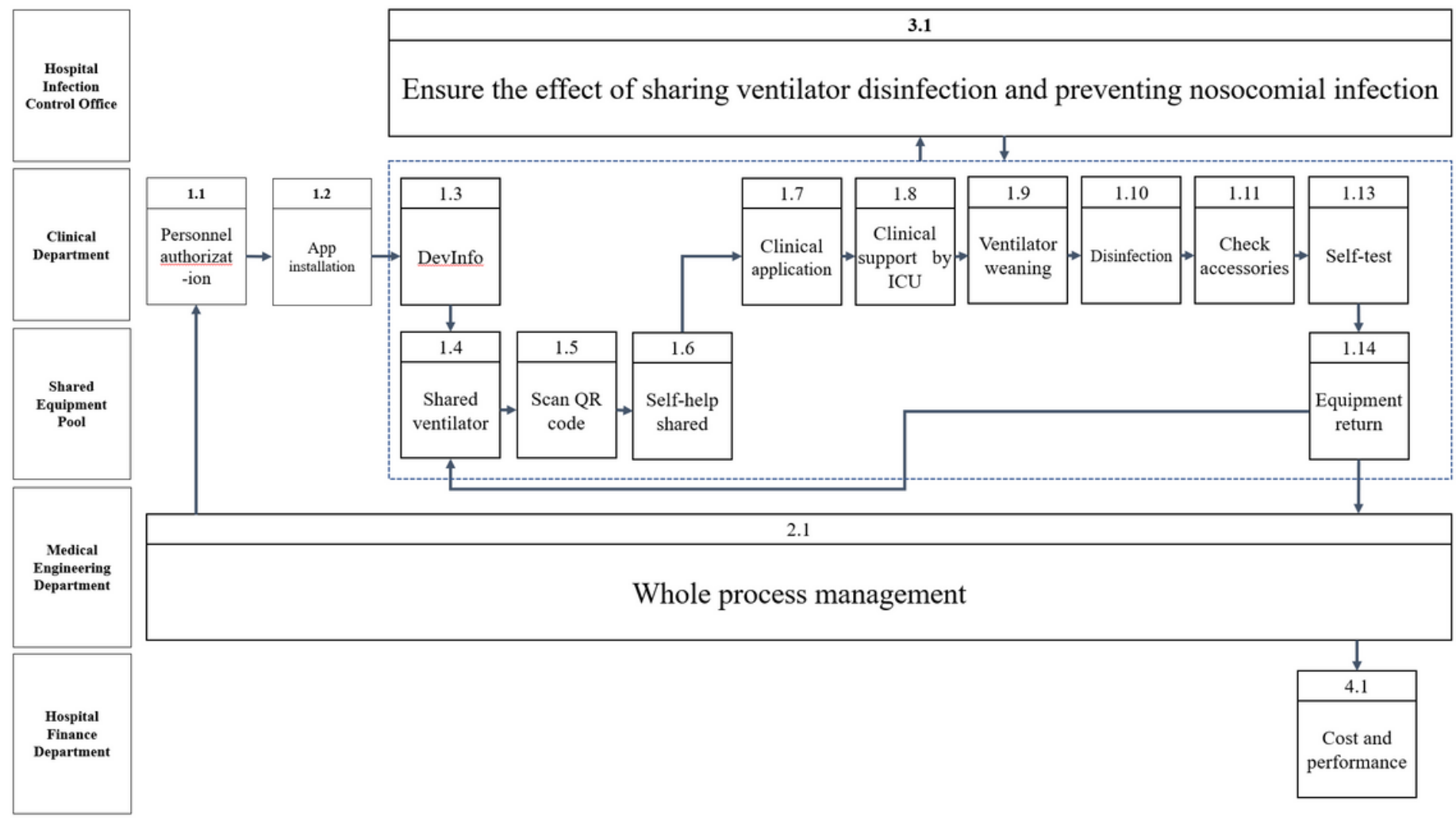

Figure 1

The details of the software work for the whole process of self-help sharing mode 


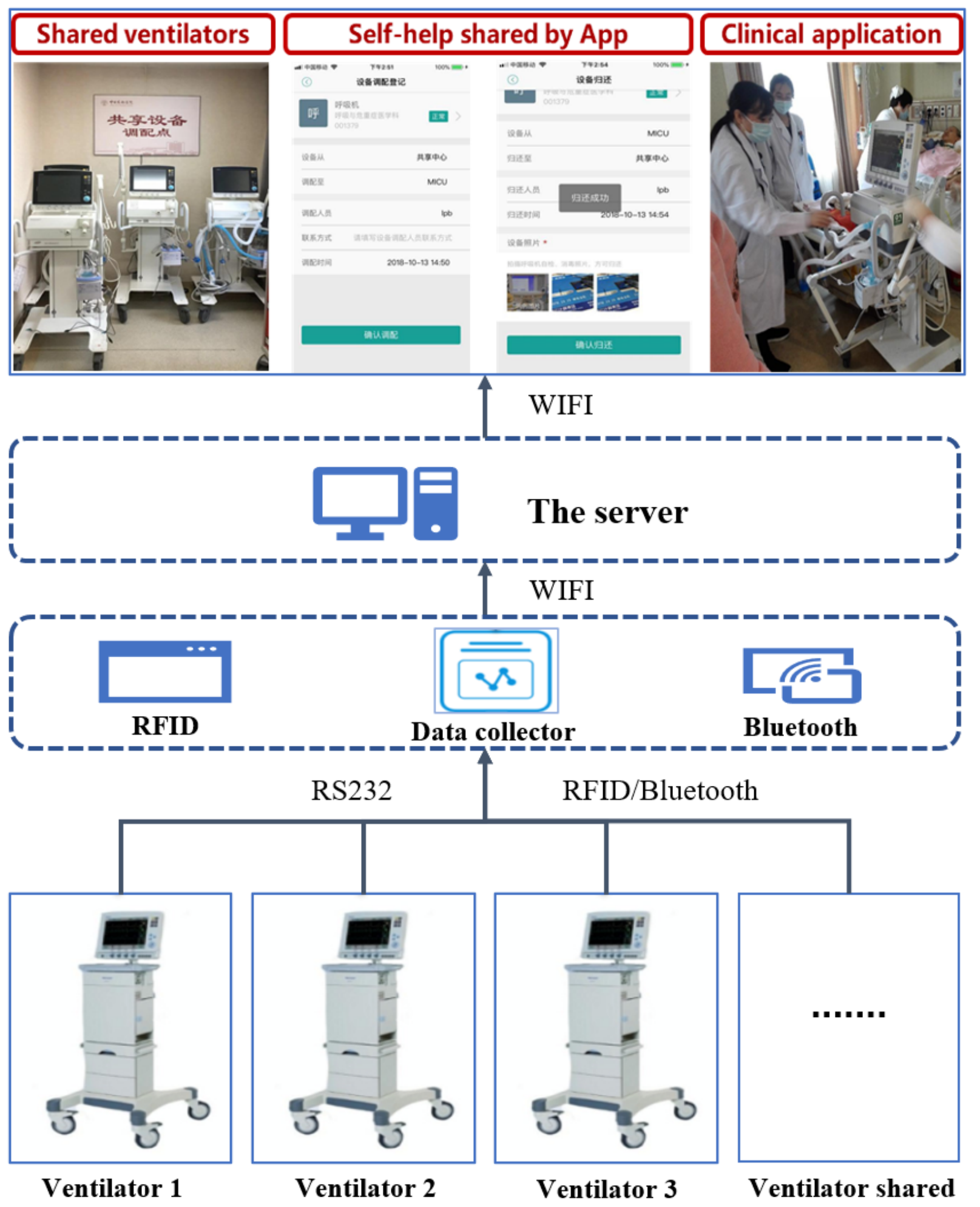

Figure 2

The construct of self-help sharing ventilator based on loT 


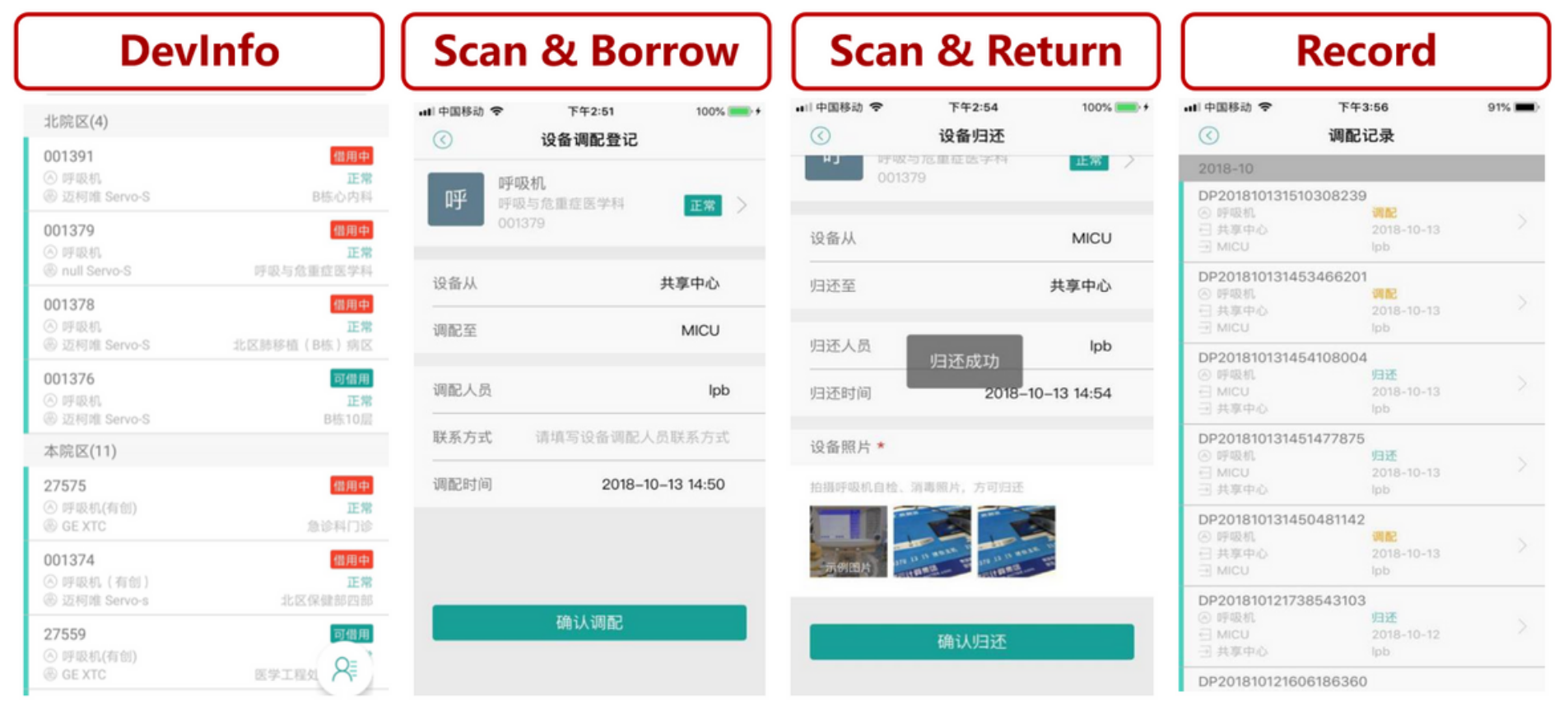

Figure 3

The mobile application for self-help sharing ventilator 